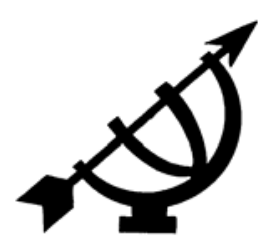

\title{
Geskrifte van N.T. van der Merwe
}

(Insluitend publikasies, geskrifte, lesings, toesprake en resensies )

VAN DER MERWE, N.T. 1958. Op weg na 'n Christelike logika. Potchefstroom: $\mathrm{PU}$ vir CHO. (M.A.-verhandeling.) Ook beskikbaar as CD by die Ferdinand Postma Biblioteek van die Noordwes-Universiteit.

VAN DER MERWE, N.T. 1962. Schematische kaarten met register behorend bij Kort overzicht van de geschiedenis der Westersche wijsbegeerte van prof. D.H.T. Vollenhoven. Amsterdam: Vrije Universiteit.

VAN DER MERWE, N.T. 1963. Aanpassing, verruiming, reformasie in die logika? Philosophia Reformata, 28(3 \& 4):147-169.

VAN DER MERWE, N.T. 1964. Objektiwiteit, sekularisasie en geskiedenis. (Voordragte November 1964 aan geskiedenisstudente. p. 200-221.) Potchefstroom. (Ongepubliseer.)

VAN DER MERWE, N.T. 1965. By Stoker in die leer. Perspektief, 3(2/3):9-17.

VAN DER MERWE, N.T. 1966. Die Eksistensialisme. Potchefstroom: PU vir CHO. (Ongepubliseer.)

VAN DER MERWE, N.T. 1967. Christelike filosofie en ideologie: die moderne tyd en die ideologie [1]. Bulletin van die Suid-Afrikaanse Vereniging vir Christelike Wetenskap, 9:83-90.

VAN DER MERWE, N.T. 1967. Christelike filosofie en ideologie: kerk en ideologie [2]. Bulletin van die Suid-Afrikaanse Vereniging vir Christelike Wetenskap, 11:210-213.

VAN DER MERWE, N.T. 1967. Christelike filosofie en ideologie: calvinistiese wysbegeerte en ideologie [3]. Bulletin van die Suid-Afrikaanse Vereniging vir Christelike Wetenskap, 11:213-220.

VAN DER MERWE, N.T. 1967. Enkele gedagtes oor lewens- en wêreldbeskouing en die taak van die Christenwetenskaplike. Perspektief, 5(4):3-19.

VAN DER MERWE, N.T. 1968. Christelike filosofie en ideologie: Calvinistiese wysbegeerte en ideologie [slot]. Bulletin van die Suid-Afrikaanse Vereniging vir Christelike Wetenskap, 12: 34-40.

VAN DER MERWE, N.T. 1968. Prof. J.P.A. Mekkes - ter geleentheid van sy 70e verjaarsdag. Perspektief, 7(1):1-4.

VAN DER MERWE, N.T. 1969. Aspekte van 'n funksionele beskouing van verbeelding en van 'n tipologie van teorieë oor die verbeelding. Philosophia Reformata, 34(3 \& 4):147-178. (Ook gelewer as voordrag by die 10 e kongres van die Vereniging ter Bevordering van Wysbegeerte in Suid-Afrika, 19 Januarie 1968.) 
VAN DER MERWE, N.T. 1969. Grepe uit die kontemporêre wysbegeerte. (In Die atoomeeu in U lig - Eeufeespublikasie. Potchefstroom: PU vir $\mathrm{CHO}$. Instituut vir die Bevordering van die Calvinisme. Reeks F3: Versamelwerke no. 1:76-112.)

VAN DER MERWE, N.T. 1969. 'n Woning vir die jeug: in die dae van jou jonkheid (In Korps Veritas Vincet. Jeug en sekularisering. Potchefstroom: Pro Rege. p. 45-77.)

VAN DER MERWE, N.T. 1971. Enkele opmerkings oor wetenskap vanuit 'n wysgerige gesigspunt. Perspektief, 10(2 \& 3):109-115.

VAN DER MERWE, N.T. 1971. Enkele trekke van die huidige samelewing en die taak van die toekoms. (Voordrag by geleentheid van die afsluitingsfunksie van die Wysgerige Studentevereniging, PU vir CHO.) Perspektief, 12(4):57-64.

VAN DER MERWE, N.T. 1971. Objektiwiteit, sekularisasie en geskiedenis. (In Truth and reality: philosophical perspectives on reality dedicated to Prof. Dr. H.G. Stoker. Braamfontein: De Jongh. p. 200-221.)

VAN DER MERWE, N.T.1972. "Christelik-nasionaal" ideaal en moontlikheid. Woord en Daad, 14(121):13-15.

VAN DER MERWE, N.T. 1972. Die Christelike universiteit, sy taak, moontlikhede en toekoms. (Streekkonferensie-indrukke Suid-Afrikaanse Vereeniging vir Christelike Wetenskap, 22 Sept. 1972. Potchefstroom. p. 59.)

VAN DER MERWE, N.T. 1973. "Qua via, philosophia?" The Idea of Christian Philosophy: essays in honour of D.H.Th. Vollenhoven. Philosophia Reformata, 38:84-96.

VAN DER MERWE, N.T. 1974. Bekroning van 'n lewenstaak: afskeidsboodskap aan drie geleerde Christene. Perspektief, 14(1):1-5.

VAN DER MERWE, N.T. 1975. Die mensbeskouing van Calvyn. Potchefstroom: $\mathrm{PU}$ vir $\mathrm{CHO}$. (Dosentepublikasie.)

VAN DER MERWE, N.T. 1975. Paradigm, science and society: Festschrift vir J.A.L. Taljaard. Koers, 40(4):328-358.

VAN DER MERWE, N.T. 1976. Enkele bakens in die kontemporêre wysgerige navorsing oor Aurelius Augustinus: navorsingsverslag. Potchefstroom: PU vir CHO. (Ongepubliseer.)

VAN DER MERWE, N.T. 1976. Wysbegeerte. (In Geskiedenis in die wetenskap. Wetenskaplike bydraes van die $\mathrm{PU}$ vir $\mathrm{CHO}$. Reeks A: Geesteswetenskappe, 22. Potchefstroom: PU vir CHO. p. 133-142.)

VAN DER MERWE, N.T. 1977. Wysheid en teken. Inougurele rede gehou 6 Mei 1977. Potchefstroom: PU vir CHO. (Dosentepublikasie.)

VAN DER MERWE, N.T. 1979. Resensie van Woord en wetenskap, gedenkbundel aan prof. dr. F.J.M. Potgieter. Koers, 44(4):303-310.

VAN DER MERWE, N.T. 1980. Christenjeug en gesag: inleiding. (In PU vir $\mathrm{CHO}$. Wetenskaplike bydraes van die PU vir CHO. Reeks F: Instituut vir Reformatoriese Studie. Reeks F3: Versamelwerke 11. Potchefstroom p. 15.)

VAN DER MERWE, N.T. 1981. Rationality and Scripture. (Congress organized by Calvin College, Grand Rapids, Free University, Amsterdam, and The Institute of Christian Studies, Toronto, 3-8 August 1981.) Toronto: Canada.

VAN DER MERWE, N.T. 1981. Voorwoord van eindredakteur. (Publikasieprojek Wetenskap in $U$ lig: interpretasie en oordeel. 'n Bundel opstelle uit die Fakulteit Lettere en Wysbegeerte, 1, 2(1):3-5.) Potchefstroom: PU vir $\mathrm{CHO}$. 
VAN DER MERWE, N.T. 1982. Calvin, Augustine and Platonism: a few aspects for Calvin's philosophical background. (In PU vir CHO. Calvinus reformator: his contribution to theology, church and society. Potchefstroom. Wetenskaplike bydraes van die PU vir CHO. Reeks F3: Versamelwerke, 17:69-84.)

VAN DER MERWE, N.T. 1983. Die gebruik van metode in die filosofie, spesiaal in die reformatoriese tradisie. Koers, 48:167-184.

VAN DER MERWE, N.T. 1983. Rationality and Scripture. (In Hart, H., Van der Hoeven, J. \& Wolterstorff, N., eds. Rationality in the Calvinian tradition. Lanham: University Press of America. p. 319-359.)

VAN DER MERWE, N.T. 1985. Lewens- en wêreldbeskouing in die tagtigerjare. Koers, 50(4):272-280.

VAN DER MERWE, N.T. 1985. Mens en samelewing: voorwoord van die eindredakteur. Potchefstroom: PU vir $\mathrm{CHO}$. (Potchefstroomse studies in Christelike wetenskap. Reeks J2: Monografieë, 2(2):4-7.)

VAN DER MERWE, N.T. 1986. Oor dorings en distels in die menslike lewe (die dilemma vir die Christen). Reguit (publikasie van die Filosofieetiekvereniging), $1(2 \& 3): 7-11$.

VAN DER MERWE, N.T. 1987. Thinking about thinking: a philosohical evaluation of the contribution of Edward de Bono to the logical geography of forms of thought. (Paper to be read at the Extraordinary World Congress of Philosophy on "Man, nature and history" at the Universidad Nacional de Cordoba. Argentine, September.)

VAN DER MERWE, N.T. 1988. Terrorists or freedom fighters? Orientation, 50/51:129-138.

VAN DER MERWE, N.T. 1991. Kultuurverskeidenheid in Afrika: verleentheid of geleentheid? Opening en inleiding. Potchefstroom: PU vir CHO. (Reeks F: Instituut vir Reformatoriese Studie. Reeks F3: Versamelwerke, 40:11-17.)

VAN DER MERWE, N.T. 1992. 'n Retractio. (Afskeidsrede.)

VAN DER MERWE, N.T. 1993. Prof. H.G. Stoker (4 April 1899-16 Mei 1993): 'n huldeblyk. Koers, 58(3):267-273.

VAN DER MERWE, N.T. 1994. H.G. Stoker as mentor. Koers, 59(3/4):363-376.

VAN DER MERWE, N.T. 2000. Die IRS - 'n kragsentrale van Bybelgetroue denke: dankwoord aan prof. dr. B.J. van der Walt. Koers, 65(1):163-166.

VAN DER MERWE, N.T. 2000. Wonders: kan ons daarin glo? deur B.J. van der Walt - boekbespreking. In die Skriflig, 34(2):315-317.

VAN DER MERWE, N.T. s.a. Bakens in die Christelike kenteorie. Potchefstroom: Dept. Wetenskapsleer, PU vir CHO.

VAN DER MERWE, N.T. s.a. Christian literature for Africa: word of welcome at the reception offered by the Potchefstroom University for Christian Higher Education. Orientation, 52/53/54:196-199. (Dosentepublikasie.)

VAN DER MERWE, N.T. s.a. Enkele gedagtes oor Augustinus en Calvyn. Potchefstroom: PU vir CHO. (Dosentepublikasie.)

VAN DER MERWE, N.T. s.a. Filosofie en die geskiedenis van filosofie. Potchefstroom: PU vir CHO. (Dosentepublikasie: 133-142.)

VAN DER MERWE, N.T. s.a. Lewensbeskouing en wetenskap. Potchefstroom: Dept. Wetenskapsleer, PU vir CHO.

VAN DER MERWE, N.T. 2004. (Posthuum.) On the trial of John Calvin's philosophy of language: a few notes on his commentary on Genesis 10 and 11. (In De Boer, Erik A. \& D'Assonville, Victor jr., eds. Ad Fontes: Festschrift vir Ludi Schulze. Bloemfontein: Universiteit van die Vrystaat. (Acta Theologica Supplementum, 5:117-137.) 
VAN DER MERWE, N.T. 2006. (Posthuum.) Stoker Hendrik Gerhardus. (In Campbell-Jack, C, \& McGrath, G.J., eds. New dictionary of Christian apologetics. Leicester: InterVarsity. p. 678-679.)

BEIJK, A.A. \& VAN DER MERWE, N.T. 1994. H.G. Stoker as student - die wysgerige denkklimaat en akademiese wisselwerking met Scheler en Buytendijk. Koers, 59(3/4):501-528. 